\title{
Buried Bumper Syndrome: A Case Report of a Rare Complication of Percutaneous Endoscopic Gastrostomy
}

\author{
Daniel Paramythiotis ${ }^{\mathrm{a}, \mathrm{b}}$, Konstantinia Kofina ${ }^{\mathrm{a}}$, Vassileios Papadopoulos ${ }^{\mathrm{a}}$, \\ Antonios Michalopoulos ${ }^{\mathrm{a}}$
}

\begin{abstract}
Percutaneous endoscopic gastrostomy (PEG) is thought to be a, relatively, safe procedure with a low rate of complications. Buried bumper syndrome (BBS) is the migration of the internal fixation device of PEG (bumper) out of the stomach and consists of a major and, usually, late complication with potentially lethal results. We present a case of such complication resulting in an extended anterior abdominal wall necrosis. An 87-year-old woman with a PEG placement 6 months before, due to Alzheimer's disease and inability of oral feeding, presented in a severe septic condition and with necrotic inflammation of the abdominal wall. Computerized tomography confirmed the migration of internal bumper subcutaneously. Excision of the gastrostomy and surgical debridement was performed, but, due to the patient's deteriorated condition, she died after 24 hours. PEG is ideal for patients with swallowing deficiencies, but severe complications may occur. Prevention and initiate diagnosis of the BBS are important for an early treatment, in order to avoid such severe complications.
\end{abstract}

Keywords: Percutaneous endoscopic gastrostomy; Buried bumper syndrome; Necrotizing fasciitis

\section{Introduction}

Percutaneous endoscopic gastrostomy (PEG) is considered a quite safe method of feeding patients with swallowing disabilities, who require long-term enteral nutrition. However, complications of the procedure minor or major are referred and present in a rate varying from $0.4 \%$ to $22.5 \%$ [1].

Buried bumper syndrome (BBS), the migration of the internal fixation device (bumper) out of the stomach, to the gastric wall and even to the abdominal wall, is a major and usually

\footnotetext{
Manuscript accepted for publication June 29, 2016

${ }^{a} 1$ st Propedeutic Surgical Department, A.H.E.P.A. University Hospital, Aristotle's University of Thessaloniki, Greece

${ }^{b}$ Corresponding Author: Daniel Paramythiotis, 1st Propedeutic Surgical Department, A.H.E.P.A. University Hospital, Aristotle's University of Thessaloniki, Greece. Email: danosprx1@hotmail.com
}

doi: http://dx.doi.org/10.14740/jmc2569w late complication of PEG leading in most of cases to severe intra-abdominal or abdominal wall infection. Its incidence ranges between $0.3 \%$ and $2.4 \%$ [2], but, according to others, it can occur in $0.9 \%$ to over $8 \%$ [3] of adult patients with PEG. Although this complication is considered as late one, early cases have also been described [4], probably by vigorous traction of the cannula or tightness of the external bolster [1].

We report a case of a female patient who underwent a PEG placement 6 months previously, and presented with an extensive abdominal soft tissue inflammation, due to the translocation of the bumper subcutaneously.

\section{Case Report}

An 87-year-old female patient was admitted in the emergency department in severe septic condition, presenting a soft tissue necrotic inflammation of the anterior abdominal wall. The patient suffered from final stage of Alzheimer's disease and a PEG was placed 6 months before the admission.

The terminal stage of dementia made the patient unable to communicate, and her relatives did not report any change of behavior or other symptoms on her behalf. On clinical examination, crepitus was found in the major part of anterior abdominal wall which was reddish (Fig. 1). Complete laboratory

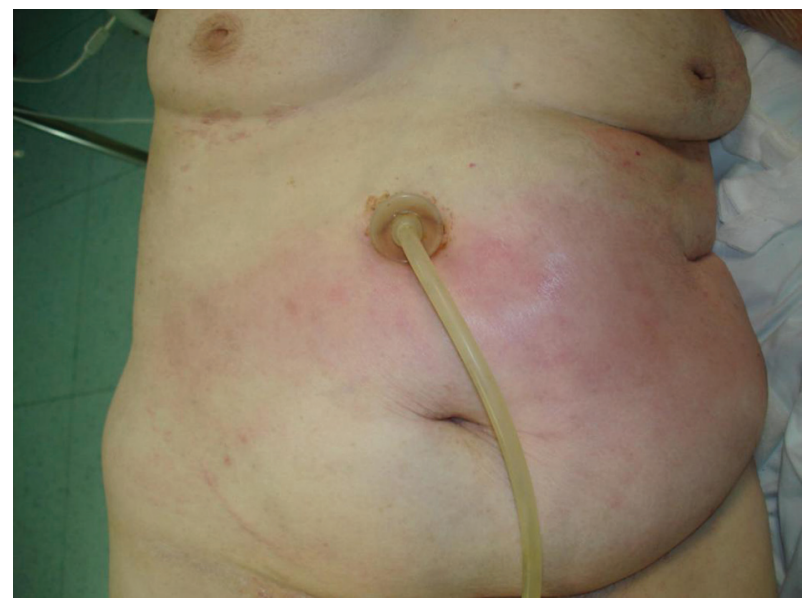

Figure 1. During admission, the whole anterior abdominal wall was seen reddish and inflamed. 

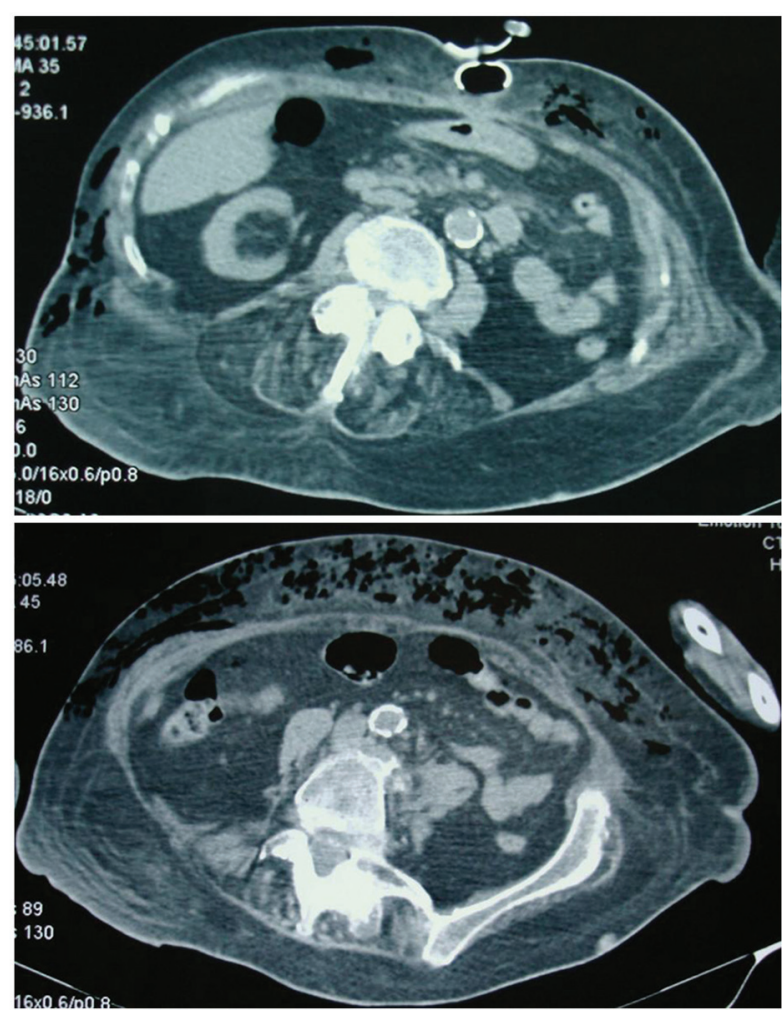

Figure 2. Abdominal CT revealing the bumper migration, subcutaneously, and presence of subcutaneous emphysema.

values showed $9,000,000 / \mu \mathrm{L}$ white blood cells with $84 \%$ neutrophils, hemoglobin $8 \mathrm{~g} / \mathrm{dL}$, hematocrite $25.2 \%$, urea $80 \mathrm{mg} /$ $\mathrm{dL}$, creatinine $1.58 \mathrm{mg} / \mathrm{dL}, \mathrm{K}^{+} 4 \mathrm{mmol} / \mathrm{L}, \mathrm{Na}^{+} 126 \mathrm{mmol} / \mathrm{L}$ and $\mathrm{Ca}^{2+} 7.90 \mathrm{mmol} / \mathrm{dL}$.

Further imaging examination through CT scan of the abdomen showed dislodgement of the internal bumper of the gastrostomy tube to the subcutaneous area, as well as an extensive subcutaneous emphysema of the anterior abdominal wall, followed by necrosis (Fig. 2).

After thorough information, relatives' consent was obtained and the surgical intervention was decided. Intra-operatively, the abdominal wall was opened and explored extensively; PEG was retracted as the internal bumper rested subcutaneously and the necrotic regions were removed (Fig.
3). Tissues from the wound, as well as the PEG tip, were selected for cultures and sensitivity test and the patient was immediately administered wide-range antibiotics. Although she was, hemodynamically, full supported, the patient died the next day, due to septic shock. The culture revealed the presence of E. coli, sensitive at amoxicillin, clavulanic and imipenem.

\section{Discussion}

PEG was realized for the first time by Gauderer et al in 1980 [5], for long-term enteral feeding without the need of an open surgery. Since then, PEG has been widely used for feeding patients with poor oral intake, such as in cases of neurologic or mechanical dysphagia and in the critically ill. It provides a more natural nutrition than parenteral feeding and is thought to be a safe procedure, even for the elder patients [6].

The overall complication rate after PEG placement ranges between $2 \%$ and $23.8 \%$ of cases, according to Biswas et al [7]. These complications can be minor, as wound infection, or major, as necrotizing fasciitis or peritonitis [7]. They can also be classified in mechanical (tube obstruction, malposition, secondary displacement or removal, leakage, skin erosion, intestinal obstruction or perforation, bleeding), infectious (infection of the insertion site, aspiration, peritonitis) and metabolic complications (electrolyte and glucose disturbances) [8].

BBS was first reported as a complication in 1988 by Levant et al and it is considered as a late and major complication, presenting with leakage, peristomal pain and infection and difficulty of feeding through the tube [9]. It consists of migration of the internal bumper in the gastric wall (incomplete type) or anywhere outside the gastric lumen (complete type). It, usually, occurs after a 4-month period from PEG placement, as in our case, but cases of acute BBS presentation have also been reported [10]. Many risk factors have been proposed, but, actually, obesity and increased tension of the tube are certain reasons that lead to this condition [10].

BBS may present with bleeding, perforation [1], peritonitis, abscess and phlegmon [7], but also, rarely, as necrotizing fasciitis [11], rectus abdominis necrosis [12], or with co-existence of encephalopathy and high anion gap metabolic acidosis [13]; these complications could be potentially lethal. Microbes isolated from the tube or the wound are rarely described in the literature, but they can include Klebsiella pneumonia and

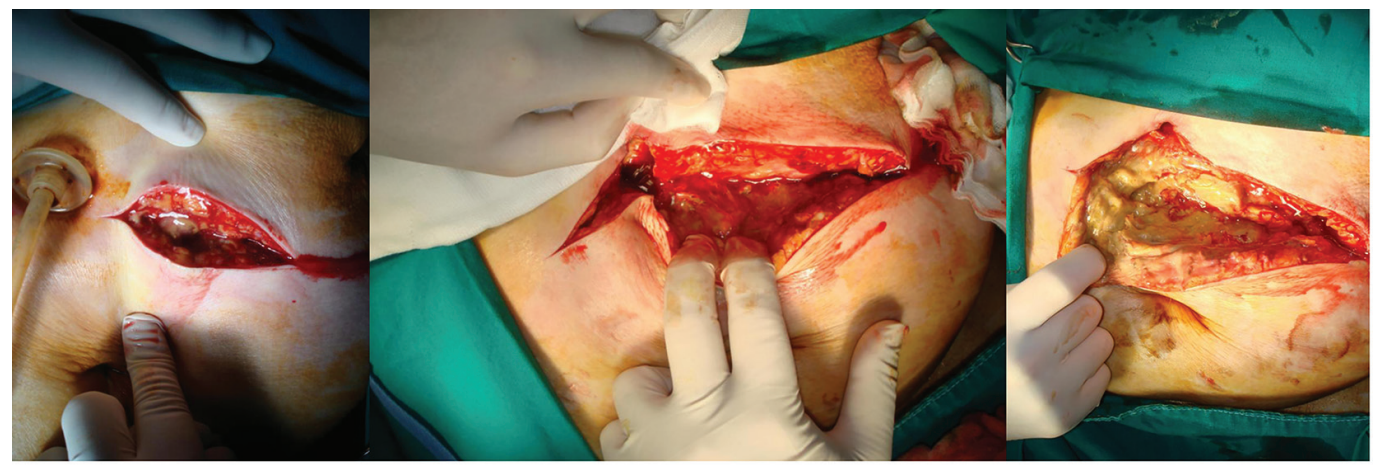

Figure 3. Extensive exploration of the abdominal wall, PEG extraction, debridement and collection of tissues for culture. 


\section{Candida vulgaris [7].}

When BBS does occur, the removal of the tube is necessary for the prevention of secondary complications. Although endoscopic or surgical retrieval, open or laparoscopic, can be performed $[14,15]$, new methods have also been described, such as NOTES [16]. However, efforts to re-introduction of the bumper in the stomach, through endoscopy, have also been reported [17]. Furthermore, necrotic fasciitis, which consists of a usually lethal condition, has been reported to be treated with early and aggressive surgical debridement, antibiotic administration and supportive therapy [18].

In patients suffering from dementia or brain injury, who are not able to communicate and report their symptoms to their family members or caregivers, the initial clinical condition could be misleading [19] and, therefore, they may not be examined and treated in time. Our patient could not reveal any signs of pain or discomfort in the inflammatory area, so her condition misinterpreted to local skin irritation, before the presence of high fever, which increased the family's concerns. However, as in our case, a suspected and earlier diagnosis could have prevented any further intraperitoneal or subcutaneous administration of feeding via the PEG, as well as earlier treatment of necrotic fasciitis.

\section{Conclusion}

BBS is a rare complication of the PEG placement. Safe positioning of the external bolster is important for the prevention of this complication. However, in cases of internal bumper migration, early diagnosis and treatment are crucial for the prevention of further complications; if not treated on time, the results could be severe and even lethal. Cooperation between doctors, nurses, family, or care-givers can lead to prevention and a better confrontation of the condition.

\section{Conflicts of Interest}

The authors declare that there are no conflicts of interest regarding this paper.

\section{Funding}

None.

\section{Grant Support}

None.

\section{References}

1. Cyrany J, Rejchrt S, Kopacova M, Bures J. Buried bumper syndrome: A complication of percutaneous endoscopic gastrostomy. World J Gastroenterol. 2016;22(2):618-627.
2. Kurek K, Baniukiewicz A, Swidnicka-Siergiejko A. Buried bumper syndrome: a rare complication of percutaneous endoscopic gastrostomy. Wideochir Inne Tech Maloinwazyjne. 2015;10(3):504-507.

3. Richter-Schrag HJ, Fischer A. [Buried bumper syndrome: A new classification and therapy algorithm]. Chirurg. 2015;86(10):963-969.

4. Geer W, Jeanmonod R. Early presentation of buried bumper syndrome. West J Emerg Med. 2013;14(5):421423.

5. Gauderer MW, Ponsky JL, Izant RJ, Jr. Gastrostomy without laparotomy: a percutaneous endoscopic technique. J Pediatr Surg. 1980;15(6):872-875.

6. Oh DJ, Kim B, Lee JK, Kang HW, Kim JH, Lim YJ, Koh MS, et al. Can percutaneous endoscopic gastrostomy be carried out safely in the elderly? Geriatr Gerontol Int. 2016;16(4):481-485.

7. Biswas S, Dontukurthy S, Rosenzweig MG, Kothuru R, Abrol S. Buried bumper syndrome revisited: a rare but potentially fatal complication of PEG tube placement. Case Rep Crit Care. 2014;2014:634953.

8. Blumenstein I, Shastri YM, Stein J. Gastroenteric tube feeding: techniques, problems and solutions. World $\mathrm{J}$ Gastroenterol. 2014;20(26):8505-8524.

9. Levant JA, Drennen F, McDonald GB. Retraction of the Sacks-Vine gastrostomy tubes into the gastric wall: report of seven cases. Gastrointest Endosc. 1988;34:215.

10. Pop GH. Buried bumper syndrome: can we prevent it? Practical Gastroenterology 2010; 34(5):8-13.

11. Tenembaum D, Inayat F, Rubin M. Necrotizing fasciitis secondary to acute buried bumper syndrome. Clin Gastroenterol Hepatol. 2015;13(3):A17-18.

12. Johnson T, Velez KA, Zhan E. Buried bumper syndrome causing rectus abdominis necrosis in a man with tetraplegia. Spinal Cord. 2010;48(1):85-86.

13. Lopez EM, Ghetmiri E, Gettle LM, Reed MF, McAllister BP. Encephalopathy and high anion gap metabolic acidosis: an unusual herald of buried bumper syndrome. Lancet. 2015;385(9969):744.

14. Ehsan S, Dyall L, Ubhi S. A novel laparoscopic approach for the surgical management of buried bumper syndrome. Ann R Coll Surg Engl. 2012;94(1):61-62.

15. Born P, Winker J, Jung A, Strebel H. Buried bumper--the endoscopic approach. Arab J Gastroenterol. 2014;15(2):82-84.

16. Nennstiel S, Schlag C, Meining A. [Therapy of Buried Bumper Syndrome via NOTES - A Case Report]. Z Gastroenterol. 2013;51(8):744-746.

17. Taher MM, Kosai NR, Gendeh HS. Creative treatment of early buried bumper syndrome. Ann R Coll Surg Engl. 2014;96(8):621-622.

18. Misiakos EP, Bagias G, Patapis P, Sotiropoulos D, Kanavidis $P$, Machairas A. Current concepts in the management of necrotizing fasciitis. Front Surg. 2014;1:36.

19. Krull CM, Dennison AC. A Case Series: The Identification of Buried Bumper Syndrome With Abdominal Computed Tomography Scan in Two Severely Brain Injured Rehabilitation Patients. PM R. 2016. 